\title{
Delay in the Diagnosis of Oral Malignancy: Study on Responsible Factors
}

\author{
Nurul Karim Chowdhury ${ }^{*}$ \\ Kyaw Khin $U^{1}$ \\ Ziaul Answar Chowdhury ${ }^{2}$ \\ Md. Abbas Uddin ${ }^{3}$ \\ H S Mubarak Hossain ${ }^{1}$ \\ Supran Biswas ${ }^{1}$ \\ Mostafa Mahfuzul Anwar ${ }^{1}$
}

\author{
'Department of ENT \& Head-Neck Surgery \\ Chittagong Medical College \\ Chattogram, Bangladesh. \\ ${ }^{2}$ Department of ENT \\ 250 bedded Chattogram General Hospital \\ Chattogram, Bangladesh. \\ ${ }^{3}$ Department of ENT \& Head-Neck Surgery \\ BGC Trust Medical College \\ Chattogram, Bangladesh.
}

\begin{abstract}
Background : Oral malignancy is an emerging disease all over the world. Treatment failure is grave if the diagnosis is delayed in this disease which will ultimately increase the mortality rate. This is an observational sociodemographic study, done to identify the causes in diagnostic delay of the patients suffering from oral cancer.

Materials and methods: The study was done with a sample size of 215 cases of oral cancer patients. This observational study was conducted from $1^{\text {st }}$ August 2015 to $31^{\text {st }}$ December 2016 at Upazila Health Complex, Mirsarai, Chattogram \& later at ENT Department of Chittagong Medical College Hospital from $1^{\text {st }}$ March 2017 to $30^{\text {th }}$ April 2018
\end{abstract}

Results: Several causes of diagnostic delay were identified. Among them, monetary issue (78\%) and Ignorance or Illiteracy (69\%) have been found as the most important causes. Stage of the disease, delay in referral system, tobacco use, age, gender, alternative medicine, social taboo, distance of hospital from house etc were found the other factors delaying the diagnosis of the cancer.

Conclusion: Many of the causes of delay can be preventable. The authority should establish awareness among the patients \& a protocol for early detection of cancer by the health professionals.

Key words: Oral cancer; Diagnosis; Mouth ulcer.

\section{INTRODUCTION}

Survival rates in oral cancer is one of the lowest worldwide. Approximately 50\% of these malignancies are diagnosed at stage III or IV with 5-years survival rates ranging from $20 \%$ to $55 \%{ }^{1}$. Maximum patients return with recurrence within 2 years after treatment or surgery ${ }^{2}$. Diagnostic delay in these type of cancers is a very important matter in determining the outcome of the disease process. This issue is more important for Bangladesh, as oral cancer is highly prevalent in this resourseless developing country. An early diagnosis \& management will lead to a better outcome of the disease and it will make the treatment less expensive \& easily available for the patients \& will increase survival rate eventually.

\section{MATERIALS AND METHODS}

This observational study was conducted with sample size of 215 from $1^{\text {st }}$ August 2015 to $31^{\text {st }}$ December 2016 at Upazila Health Complex, Mirsarai, Chattogram \& later at ENT Department of Chittagong Medical College Hospital from $1^{\text {st }}$ March 2017 to $30^{\text {th }}$ April 2018. Health care seeking behavior of the patients, their socioeconomic conditions, difficulties in the health care delivery and referral systems were assessed to identify the delay between the appearance of symptoms and seeking medical treatments.

Patients who were physically unfit to respond to the study (Such as unable to open the mouth properly, patient with tracheostomy tube, with other severe co morbid disease) non-cooprative or terminally ill patients were excluded from the study. 
Patients were thoroughly examined, medical documents were checked \& noted, new investigations done where possible \& needed \& diseases were staged clinically. Patients interviews were documented in a pre designed data sheet \& questionnarie.

\section{RESULTS}

The mean age (Mean \pm Standard deviation) of the patients were $55( \pm)$ years with age range of 26-85 years. People in the age group of 55-64 years were affected most $(33.95 \%)$ and the least affected age group was 25-34 yrs (1.86\% ) (Table I).

Table I : Age distribution of the patients.

$\begin{array}{lcc}\text { Age group (In years ) } & \text { Number } & \text { Percentage } \\ 25-34 & 4 & 1.86 \% \\ 35-44 & 32 & 14.88 \% \\ 45-54 & 60 & 27.90 \% \\ 55-64 & 73 & 33.95 \% \\ 65-74 & 30 & 13.95 \% \\ >74 & 16 & 7.44 \% \\ \text { Total } & 215 & 100 \%\end{array}$

In the study, most of the patients were found in the advanced stage of oral malignancy, stage-III (31.6\%), within stage III, most patients are of age group 55-64 years. Again, patients from age group 55-64 is mostly presented as stage IV also.

Table II : Stages of the disease according to the Age groups.

\begin{tabular}{lrrrrrrr} 
Stage & \multicolumn{4}{c}{ Age groups } & \multicolumn{2}{r}{ Total (Parcentage) } \\
& $\mathbf{2 5 - 3 4}$ & $\mathbf{3 5 - 4 4}$ & $\mathbf{4 5 - 5 4}$ & $\mathbf{5 5 - 6 4}$ & $\mathbf{6 5 - 7 4}$ & $>\mathbf{7 4}$ & in stage \\
Stage- I & 01 & 10 & 11 & 09 & 03 & 03 & $37(17.2 \%)$ \\
Stage- II & 02 & 14 & 10 & 12 & 15 & 02 & $55(25.5 \%)$ \\
Stage- III & 01 & 05 & 19 & 30 & 06 & 07 & $68(31.6 \%)$ \\
Stage- IV & 00 & 03 & 20 & 22 & 06 & 04 & $55(25.5 \%)$ \\
\hline
\end{tabular}

There is significant relationship between diagnostic delay and literacy rate. Within 215 patients, $60.93 \%$ were found illiterate.

Table III : Literacy and primary delay.

\begin{tabular}{lcc} 
Level of education & Number of patients & Parcentage \\
Illiterate & 131 & $60.93 \%$ \\
Literate & 84 & $39.07 \%$ \\
Total no. of patients & 215 & $100 \%$ \\
\hline
\end{tabular}

There is also a relationship between stages of oral cancer with the living area of the patients. $59.53 \%$ patients were residing at Urban area and rest residing at village area. Urban people were found more aware about disease as maximum patient reported at stage II (Total 44 in number ) where maximum rural patients (Total 38 in number) reported at stage III.
Table IV : Stages of the disease according to the residance of the patients seeking treatment in the hospital.

\begin{tabular}{lrcc} 
Stage & $\begin{array}{c}\text { Patients living in } \\
\text { Urban area }\end{array}$ & $\begin{array}{c}\text { Patients living in } \\
\text { Rural area }\end{array}$ & $\begin{array}{c}\text { Total (Parcentage) } \\
\text { in Stage }\end{array}$ \\
Stage I & 28 & 09 & $37(17.2 \%)$ \\
Stage II & 44 & 11 & $55(25.5 \%)$ \\
Stage III & 30 & 38 & $68(31.6 \%)$ \\
Stage IV & 26 & 29 & $55(25.5 \%)$ \\
Total Patients & $128(59.53 \%)$ & $87(40.46 \%)$ & $215(100 \%)$ \\
\hline
\end{tabular}

There is significant relationship between delay in cancer treatment and patients view about cancer. Highest number of patients of the this study have lack of knowledge about cancer and its outcome. The number is 95 (44.18\%). A good number (61) patients didn't pay attention about the disease thinking it as a small mouth ulcer and it will heal after sometime.

Table V : View of the patients about cancer.

\begin{tabular}{lcc} 
Idea about cancer & No. of patients & Parcentage \\
Ill fate & 02 & $0.93 \%$ \\
Costly & 06 & $2.79 \%$ \\
Small mouth ulcer & 61 & $28.37 \%$ \\
Avoidance due to fear & 19 & $8.83 \%$ \\
Prolonged treatment & 30 & $13.95 \%$ \\
Lack of knowledge & 95 & $44.18 \%$ \\
Others & 02 & $0.93 \%$ \\
\hline
\end{tabular}

Table VI : Delay in referral from $1^{\text {st }}$ attending doctor.

\begin{tabular}{lcrr}
$\begin{array}{l}\text { Referral from } \mathbf{~}^{\text {st }} \\
\text { attending doctor }\end{array}$ & $\begin{array}{c}\text { Delay of less } \\
\text { than } \mathbf{3} \text { months }\end{array}$ & $\begin{array}{c}\text { Delay of more } \\
\text { than } \mathbf{3} \text { months }\end{array}$ & Total \\
Yes & 63 & 98 & $161(74.88 \%)$ \\
No & 19 & 35 & $54(25.11 \%)$ \\
Total & $82(38.13 \%)$ & $133(61.86 \%)$ & $215(100 \%)$ \\
\hline
\end{tabular}

As Bangladesh is a low middle income country, it is seen that financial problem is the most important cause $(36.27 \%)$ in getting delayed treatment. Ignorance of the patients $(32.09 \%) \&$ belief in religious prayer for disease cure $(9.30 \%)$ are other important causes.

Table VII : Causes of delay in getting treatment from tertiary level hospital/specialized cancer hospital.

\begin{tabular}{lcc} 
Cause & No. of patients & Percentage \\
Belief in other medicine & 12 & $5.58 \%$ \\
Financial & 78 & $36.27 \%$ \\
Belief in Religious & & \\
prayer for cure & 20 & $9.30 \%$ \\
Ignorance & 69 & $32.09 \%$ \\
Superstition & 19 & $8.83 \%$ \\
Others & 17 & $7.90 \%$ \\
\hline
\end{tabular}




\section{DISCUSSION}

In last few decades, oral cancer is increasing day by day. Carcinoma in head neck region is the $6^{\text {th }}$ most frequent cancer in the world ${ }^{3}$. Approx. $3-5 \%$ of all carcinomas are located in the oral cavity. Over 2,70,000 of oral malignancies are diagnosed yearly worldwide ${ }^{4}$. Incidence of oral cancer is increasing in young popupation. Though the overall 5 years survival rate has not significantly improved, It is mainly due to the fact that $60 \%$ oral cancers are diagnosed in advanced stage ( III \& IV stage $)^{5}$. "Field cancerization" is an another issue due to which the risk of second primary tumour development is a significant matter. 5 years survival rate is $83 \%$ when oral cancers are treated at stage I \& II. This survival rate decreases to $42 \%$ when tumour comes with neck node metastasis \& when patient comes with distant metastasis, 5 years survival rate falls to $18 \%{ }^{6}$. Parcentage of tongue \& oropharyngeal cancer has increased in young population due to practice of Oral coitus (HPV infection) ${ }^{7}$. Men are more affected than women due to smoking, alcohol consumption \& sunlight exposure ${ }^{8}$.

Delay in diagnosis is definitely one of the most important causes of mortality of oral malignancy. Multiple factors are related with this delay in diagnosis. This is an observational study which depicts this factors with an analysis of hope that modification or removal of the discussed causes will finally reduce the delay of treatment \& ultimately improve the prognosis of the cancer.

In Bangladesh, financial crisis, poor knowledge about cancer, bad oral hygiene, poor nutritional status, Human Papilloma Virus (HPV) infection, candida species superinfection, genetic predisposition, Immunosuppression, distance of the health care facilities, disbelief in modern medicine, faith in religious prayer for cure etc are the main causes of diagnostic delay of oral cancer.

Sankara Narayanan R. told that, $41 \%$ patients of oral cancer came in 2 months, whereas $60 \%$ patient came at around 5 months. It is also found that, maximum patients came in stage III $(52 \%)$. He also noticed that $62 \%$ patient presented at late stage (III, IV) ${ }^{9}$. In our study 68 patients $(31.6 \%)$ came at stage III \& 55 patients $(25.5 \%)$ presented at stage IV. The commonest cancer found is squamous cell carcinoma in almost all the studies.
It is seen that non-healing ulcer \& pain are the most early symptoms of oral cancer mainly buccal carcinoma which constitutes the majority of the cases. So, we can make an awareness program to the common people about mouth ulcer with pain as an early symptom of oral cancer so they can come early to take advice or treatment.

Regarding hospital delay, it is found that $61.86 \%$ patients has delayed more than 3 months to report to tertiary level hospital. Other $38.13 \%$ patients reported within 3 months, within 215 patients, $74.88 \%$ were initially attended $\&$ referred by a doctor in a primary level hospital \& the rest $25.11 \%$ directly came to tertiary level hospital.

Thus, our comment regarding this study that, low socioeconomic status, illiteracy or poor knowledge about the fate of the disease, belief in religious medicine, distance of hospital from house, fear of prolonged treatment etc are closely related with diagnostic delay of oral cancer patients in our region. Similarly, lack of early consultaion with a primary physician is a contributory factor. All these factors may be used to design a proper planning of awareness programme to reduce oral cancers.

\section{CONCLUSION}

Many of the causes of delay which are mentioned earlier, can be preventable. General public \& patients should undergo a wide consensus for oral cancer screening. Regular oral and dental check up is necessary. The authority should establish awareness among the patients \& a protocol for early detection of cancer by the health professionals.

\section{DISCLOSURE}

All the authors declared no competing interest. 


\section{REFERENCES}

1. The Oral Cancer Foundation. Oral cancer facts.2017.

2. Scully C, Petti S. Overview of cancer for the healthcare team: Aetiopathogenesis and early diagnosis. Oral Oncol. 2010;35(3):305-306.

3. Noonan B. Understanding the reasons why patients delay seeking treatment for oral cancer symptoms from a primary health care professional: An integrative literature review. Eur J OncolNurs. 2014;11(2):102-104.

4. Güneri P, Epstein JB. Late stage diagnosis of oral cancer: Components and possible solutions. Oral Oncol. 2014;12(06):245-248.

5. Allen K, Farah CS. Patient perspectives of diagnostic delay for suspicious oral mucosal lesions. Aust Dent J. 2015;41(3):298-291.

6. Gómez I, Warnakulasuriya S, Varela-Centelles PI et al. Is early diagnosis oforal cancer a feasible objective? Who is to blame for diagnostic delay? Oral Dis. 2010;10(3):191-195.

7. Stroup DF, Berlin JA, Morton SC, Olkin I, Williamson GD, Rennie D et al. Meta-analysis of observational studies in epidemiology: A proposal for reporting. Meta-analysis of Observational Studies in Epidemiology (MOOSE) group.JAMA. 2000;205:2008-2009.

8. Howlader N, Noone AM, Krapcho M, Neyman N, Aminou R, Waldron W, et al., editors. SEER Cancer Statistics Review. Bethesda, MD: National Cancer Institute. 2012;1975-2008.

9. Sankara Narayanan R. Oral cancer in india: An epidemiologic and clinical review. Oral Surg Oral Med Oral path.1990;39:273-275. 